\title{
Developing the environmental humanities: A Swiss perspective
}

Forêt, Philippe ; Hall, Marcus ; Kueffer, Christoph

\begin{abstract}
The environmental humanities as a metadiscipline provide a new forum for enabling continuous and reciprocal conversations within the humanities and with other sciences in environmental research.
\end{abstract}

DOI: https://doi.org/10.14512/gaia.23.1.18

Posted at the Zurich Open Repository and Archive, University of Zurich ZORA URL: https://doi.org/10.5167/uzh-104628

Journal Article

Published Version

Originally published at:

Forêt, Philippe; Hall, Marcus; Kueffer, Christoph (2014). Developing the environmental humanities: A Swiss perspective. GAIA, 23(1):67-69.

DOI: https://doi.org/10.14512/gaia.23.1.18 


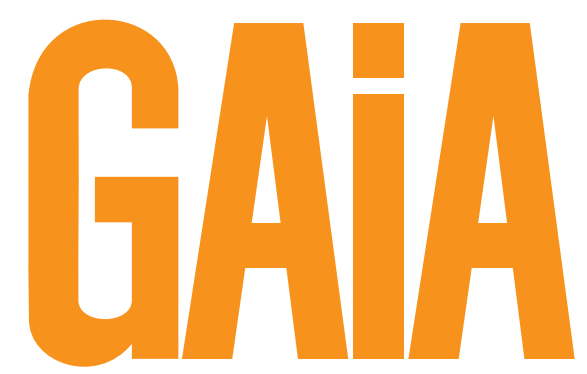

\section{1 | 2014 ECOLOGICAL PERSPECTIVES FOR SCIENCE AND SOCIETY \\ ÖKOLOGISCHE PERSPEKTIVEN FÜR WISSENSCHAFT UND GESELLSCHAFT}

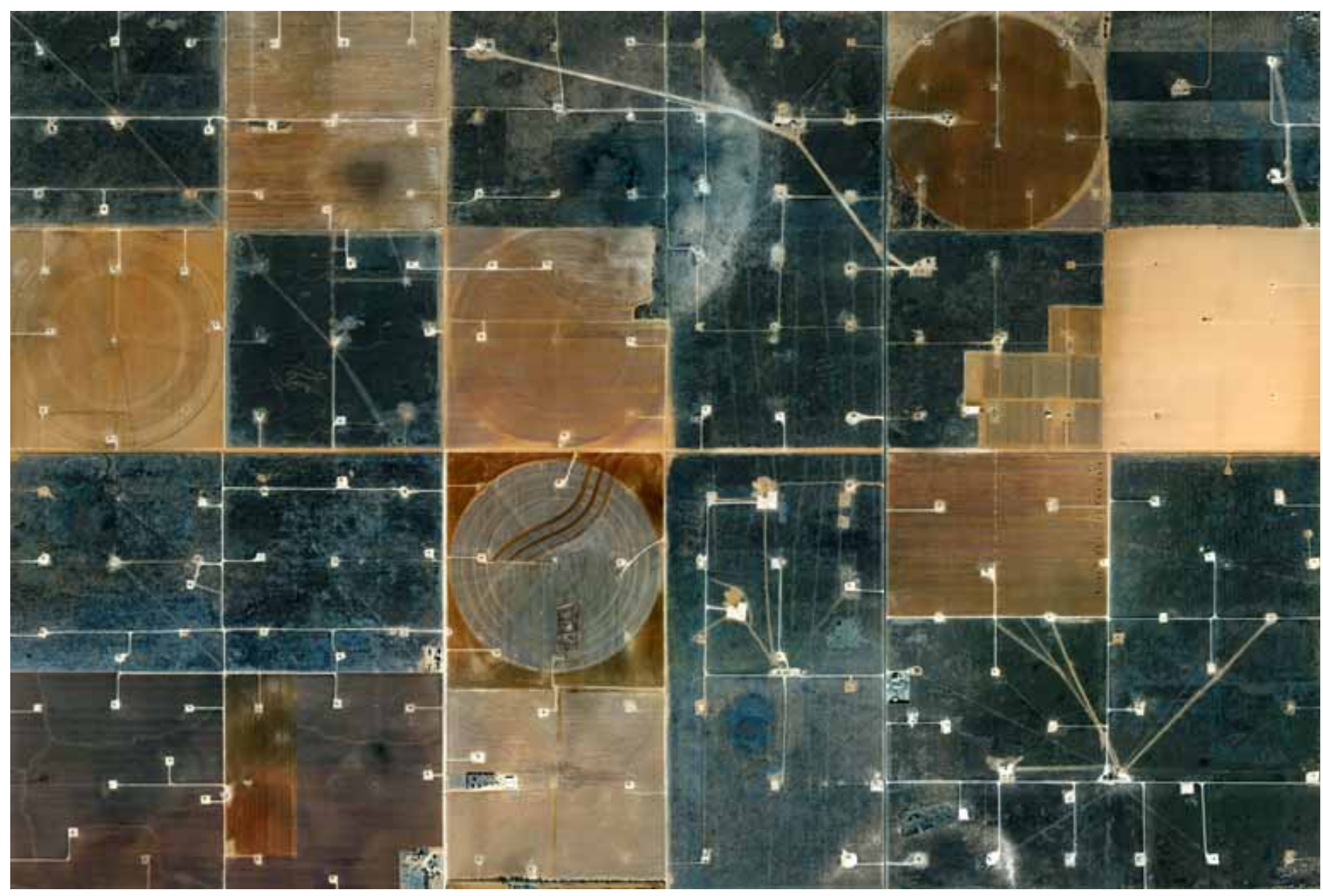

WIE KLIMASKEPTIKER ARGUMENTIEREN

- THEORIE DER TRANSDISZIPLINARITÄT

- COMMUNICATING CLIMATE CHANGE 


\section{saguf}

schweizerische akademische gesellschaft für

umweltforschung und ökologie

societé académique suisse pour la recherche sur l'environnement et l'écologie

swiss academic society for environmental research and ecology

\section{Developing the Environmental Humanities: A Swiss Perspective}

\author{
The environmental humanities as a \\ metadiscipline provide a new forum for \\ enabling continuous and reciprocal \\ conversations within the humanities and \\ with other sciences in environmental research.
}

Philippe Forêt, Marcus Hall, Christoph Kueffer

Developing the Environmental Humanities: A Swiss Perspective | GAIA 23/1 (2014): 67-69

Keywords: environmental humanities, environmental problems, interdisciplinarity, metadiscipline, science and society

$T^{\mathrm{h}}$ he enormous scope and complexity of today's environmental problems require knowledge derived from the natural and the social sciences as well as the humanities, engaging experts within and beyond universities. While there is general agreement that contributions from the humanities are essential for understanding and mitigating environmental problems, differences remain about the core questions of the humanities in environmental research, the best ways for humanists to work with each other and with natural and social scientists, and the next steps for developing environmental research in the humanities. Here we review "environmental humanities" as an emerging research field, before suggesting ways for further development in the context of Switzerland.

\section{What are Environmental Humanities?}

Environmental humanities (EH, UmweltGeisteswissenschaften/sciences humaines de l'environnement/scienze umane dell' ambiente) is an emerging field that is attracting significant institutional support around the world. ${ }^{1}$ As a metadiscipline that brings into conversation several subfields, EH seeks to offer new and more synthetic insights into cultural, historical and ethical dimensions of our most intractable environmental problems (Mathae and Birz- er 2004, Sörlin 2012, SAGW/ASSH 2012). Anthropologists, human geographers, historians, political and cultural scientists, philosophers, writers, artists, and educators are now provided with a common forum to discuss environmental concerns (Rose et al. 2012, Nye et al. 2013). This forum is also fostering a richer dialogue with biologists, engineers, environmental, medical, and social scientists, as well as with politicians and business leaders (Chapman 2007, Sörlin 2013). Such conversations are needed not only because environmental systems are increasingly shaped by humans (holding various beliefs, biases, and traditions), but also because scientific discoveries are inter-

\footnotetext{
1 Examples of new programs in environmental humanities: KTH Environmental Humanities Laboratory (Stockholm), Rachel Carson Center for Environment and Society (Munich), Stony Brook University Environmental Humanities Bachelor's Program, University of California Davis Environmental Humanities Supercluster, University of Utah Environmental Humanities Graduate Program, University of Sydney Environmental Humanities Group. Examples of new publications and digital media in environmental humanities: Environmental Humanities, Australia (founded 2012), Resilience: A Journal of The Environmental Humanities, USA (founded 2012), and RCC Perspectives series and Environment and Society Portal (both Rachel Carson Center, Munich).
}

preted and implemented in political, cultural, and economic contexts, which in turn shape the range and kinds of scientific discoveries (Oreskes and Conway 2010).

No one discipline or approach is hegemonic in its ability to provide definitive information for resolving environmental dilemmas given that these are inextricably connected to the hopes, fears, and creativity of human actors (Radkau 2008). However, by combining the experience of several disciplines, $\mathrm{EH}$ as a metadiscipline can

Contact authors: Philippe Forêt, PhD | University of St. Gallen | School of Humanities and Social Sciences (SHSS) | St. Gallen | Switzerland | E-Mail: pforet@bluewin.ch

PD Dr. Marcus Hall | University of Zurich | Institute of Evolutionary Biology and Environmental Studies | Zurich | Switzerland |

E-Mail: marc.hall@ieu.uzh.ch

PD Dr. Christoph Kueffer | ETH Zurich | Institute of Integrative Biology | Department of Environmental Systems Science | Zurich | Switzerland | E-Mail: christoph.kueffer@env.ethz.ch

Contact saguf: saguf Office | Dr. Claudia Zingerli | ETH Zurich D-USYS/CHN | 8092 Zurich | Switzerland | E-Mail: saguf@env.ethz.ch | www.saguf.ch

(C) 2014 P. Forêt et al.; licensee oekom verlag. This is an article distributed under the terms of the Creative Commons Attribution License (http://creativecommons.org/licenses/by/3.0) which permits unrestricted use, distribution, and reproduction in any medium, provided the original work is properly cited. 
contribute to greater collaborative and integrative inquiry in the humanities, which ensures that the cultural complexities of environmental problems are adequately addressed. Now is also a key moment to reassert that scientists and humanists collaborate at all stages of perceiving, designing, implementing, and interpreting research projects (compare Wäger et al. forthcoming). Humanists are needed to critically reflect on cultural contexts and value-laden assumptions that shape scientific inquiry and policy making, and to develop alternative, holistic, multicultural, and historically sensitive perspectives on environmental problems.
Yet, such transformations are promoting not only wholly new physical patterns, they also fundamentally change humannature relationships, which have deep implications for the effectiveness and predictive ability of environmental sciences (Kueffer forthcoming). Dominant narratives and worldviews need to be complemented or challenged with alternative perspectives that account for reflexivity, historicity, and local complexities of vulnerability, resilience, and risk (Hall 2003, Forêt 2007, Kupper 2012). Indeed, a better understanding of ethical, cultural, and historical dimensions of the environment may guide us out of deadlock situations, such as internation- forthcoming), or even that we can easily learn from former post-collapse societies or from modern communities now recovering from a major crisis (tsunami, earthquake, oil spill, civil war).

\section{How Can Humanities and Natural Sciences Fruitfully Interact?}

In the environmental sciences, uncertainty is pervasive and often irreducible; more science will often not significantly reduce ignorance or clarify conflicts of opinions or interests. When facts are uncertain, metaphors, stories and other rhetorical devices may fuel misinterpretation between scientists and society (Lakoff and Johnson 2003).

\section{A society's history, traditions, beliefs, concepts of justice, responsibility, and ethics are key elements for interpreting environmental problems.}

\section{Identifying Key Topics in Environmental Humanities}

Although various humanistic disciplines pay increasing attention to environmental problems, the crucial perspectives that the humanities can bring to the understanding and even resolution of these problems have hardly been acknowledged. Humanists would be well equipped to deal with topics such as values, emotions, subjectivity, complexity, and failure. EH can recast established environmental problems as cultural issues and so provide fresh ideas to environmental research.

\section{Recasting Environmental Problems as Cultural Issues}

Environmental problems are often framed by natural scientists as disturbances to natural systems, which may hinder effective societal and cultural responses. However, a society's history, traditions, beliefs, concepts of justice, responsibility, and ethics are key elements for interpreting environmental problems. For instance, natural scientists have introduced terms like "global change", "the Anthropocene", or "novel ecosystems" to address the heightening transformation of the earth's abiotic and biotic conditions by humans. al negotiations on greenhouse gases (Bolin 2007). And good predictions require anticipating simultaneous changes in both physical and cultural factors (Kueffer forthcoming). Climate change science, for instance, must strengthen its ability to account for feedbacks between changing climates and evolving human behaviors and worldviews in response to such change (Warren 2011, Forêt 2013b).

\section{Introducing New Perspectives to Environmental Research}

We live in a time of overlapping crisis. Environmental humanists can reinterpret the histories of past and contemporary crises, recovering words and images, and creating concepts needed to reclaim our common experience of trauma and of hope (Solnit 2009, Hall 2010). This includes studying post-collapse societies to examine longterm cycles in our complicated relationships with nature. All societies are postcollapse societies in the sense that they have survived natural and human-made disasters, be they floods and fires or warfare and revolution, whether in recent or ancient times (Fagan 2004). This does not mean that we have cultivated a collective memory of restoration and recovery (Hall
Thus, a novel field of study is needed to better support deliberation and reflexivity. By building a common understanding of the many contexts of knowledge production, interpretation and use, humanists and scientists together can clarify environmental communication while revealing and appreciating the complexity of our responses to the environment.

More generally, EH can employ a multicultural perspective to design better research and societal transformation processes, such as adaptive management and participatory problem solving. For example, research on international cooperation and development too often focuses on how knowledge can be transferred from a developed North to the South. EH can help to develop more equitable ways of exchanging knowledge through which a developing world can learn from mistakes of the developed world, and vice versa. Reciprocal and culturally sensitive learning might be improved in both contexts.

One such cooperative initiative is the Lithium Project at the Graduate Institute of Geneva. The project seeks to provide a common framework for energy transition by accounting for the disasters of the fossil fuel age (Forêt 2013a). 


\section{Implementing Environmental Humanities in Switzerland}

A wealthy, urban, green, and largely mountainous country, Switzerland has a strong potential for researching, teaching and outreaching of EH. Global networks in diplomacy, health, finance, and commodity trade converge in Switzerland. The country hosts major multinational corporations as well as key environmental organizations, like the International Union for Conservation of Nature (IUCN) and the World Wide Fund For Nature (WWF). Building on their renowned science and technology institutes, Swiss universities can educate global leaders while exposing them to the human and social side of environmental issues.

In order to strengthen linkages among humanists and scientists, the saguf working group for environmental humanities ${ }^{2}$ has established a Swiss Center for Environmental Humanities (SCEH). We aim to coordinate activities in EH since Swiss scholars work in relative isolation, are housed in different institutes, and are specialized in sub-fields within a given discipline. SCEH explicitly encourages participation from all of Switzerland's linguistic regions. Sample events include:

- Mountains Across Borders: An Environmental History Summer School (August 2013 in Lavin, Engadin) gathered advanced graduate students and faculty members from around the world for discussing the challenges of carrying out a major mountain history project. Topics addressed the diversity of mountain cultures and ecosystems; topography, elevation, and seasonality as dividing - or else uniting - people; dependencies and conflicts between highland and lowland peoples; preservation and restoration of mountain systems; mountains as loci of disaster or as refugia during global warming.

- Scientists as Humanists, Humanists as Scientists (June 2014, Zurich). This combined weeklong graduate seminar and symposium will bring together environmental researchers and non-academic experts. In a series of workshops, ecology graduate students will investigate historical, rhetorical, and artistic aspects of their research projects. International experts will participate in roundtables for refining the humanistic role in environmental research and its societal applications while invited leaders in business and politics will suggest vital directions for new research in EH.

- Environmental Humanities Inventory. In 2014, the Swiss Academy of Humanities and Social Sciences (SAGW) is also funding a first census of research and teaching activities relevant to $\mathrm{EH}$ at Swiss academic institutions.

\section{Conclusion}

Developing EH in Switzerland requires a broad vision that questions environmental issues through humanistic methodologies, while demonstrating to university administrators, community leaders, and funding agencies that concrete propositions can be made. Environmental research and policy making must recognize the profound role of culture in framing human-nature relationships. There is an enormous need for enabling continuous and reciprocal interactions within the humanities and with other sciences in environmental research. Our ultimate goal must be to articulate a fundamentally new way of living within the earth's natural limits, rather than sustaining unrealistic lifestyles or outdated worldviews about progress and modernity.

\section{References}

Bolin, B. 2007. A history of the science and politics of climate change. The role of the Intergovernmental Panel on Climate Change. Cambridge, UK: Cambridge University Press.

Chapman, R. 2007. How to think about environmental studies. Journal of Philosophy of Education 41/1: 59-74.

Fagan, B. 2004. The long summer. How climate changed civilization. New York: Basic Books.

Forêt, P. 2007. Kartographie der Kontinuität: Vom vormodernen Ostasien zum postmodernen Hong Kong. In: Text-Bild-Karte. Kartographien der Vormoderne. Edited by J. Glauser, C. Kiening. Freiburg: Rombach.

Forêt, P. 2013 a. La route du lithium: Comment la Chine organise le nouvel ordre énergétique mondial. Paper presented at the Festival International de Géographie. Saint-Dié, F, October 5

Forêt, P. 2013 b. Climate change: A challenge to the geographers of colonial Asia. RFIEA Perspectives 9: 21-23.

Hall, M. 2003. Plants and animals in human history. Landscape Research 28: 5-9.
Hall, M. 2010. Tempo and mode in restoration. In: Restoration and history: The search for a usable environmental past. Edited by M. Hall. New York: Routledge.

Hall, M. Forthcoming. Restoration as counter narrative. In: The Oxford handbook of environmental history. Edited by A. Isenberg. New York: Oxford University Press.

Kueffer, C. Forthcoming. Ecological Novelty: Towards an interdisciplinary understanding of ecological change in the Anthropocene. In: Grounding global climate change. Contributions from the social and cultural sciences. Edited by H. M. Greschke, J. Tischler. Berlin: Springer.

Kupper, P. 2012. Wildnis schaffen: Eine transnationale Geschichte des Schweizerischen Nationalparks. Bern: Haupt.

Lakoff, G., M. Johnson. 2003. Metaphors we live by. Chicago: University of Chicago Press.

Mathae, K., C. Birzer (Eds.). 2004. Reinvigorating the humanities: Enhancing research and education on campus and beyond. Washington, D. C.: Association of American Universities.

Nye, D. E., L. Rugg, J. Fleming, R. Emmett. 2013. The emergence of the environmental humanities. Edited by MISTRA (Swedish Foundation for Strategic Environmental Research). Stockholm: MISTRA.

Oreskes, N., E. M. Conway. 2010. Merchants of doubt. How a handful of scientists obscured the truth on issues from tobacco smoke to global warming. London: Bloomsbury.

Radkau, J. 2008. Nature and power. A global history of the environment. Cambridge, UK: Cambridge University Press.

Rose, D. B., T. van Dooren, M. Chrulew, S. Cooke, M. Kearnes, E. O'Gorman. 2012. Thinking through the environment, unsettling the humanities. Environmental Humanities 1: 1-5.

SAGW/ASSH (Swiss Academy of Humanities and Social Sciences). 2012. Positionspapier: Für eine Erneuerung der Geisteswissenschaften. Bern: SAGW/ASSH.

Sörlin, S. 2012. Environmental humanities: Why should biologists interested in the environment take the humanities seriously. BioScience 62/9: 788-789.

Solnit, R. 2009. A paradise built in hell: The extraordinary communities that arise in disaster. New York: Viking.

Sörlin, S. 2013. The changing nature of environmental expertise. Eurozine, November 19, 2013. www.eurozine.com/pdf/2013-11-19sorlin-en.pdf (accessed January 22, 2014).

Wäger, P., O. Ejderyan, F. Schmid, M. Stauffacher, C. Zingerli. Forthcoming. The roles of the social sciences and humanities in integrative research on natural resources. GAIA 23/2.

Warren, R. 2011. The role of interactions in a world implementing adaptation and mitigation solutions to climate change. Philosophical Transactions of the Royal Society A 369: 217-241. 